\title{
VIBROACOUSTIC ANALYSIS IN THE ASSESSMENT OF THE TECHNICAL CONDITION OF THE AIRCRAFT AIRFRAME COMPOSITE ELEMENTS
}

\author{
Daniel MOKRZAN ${ }^{1}$, Julia MILEWICZ ${ }^{1}$, Grzegorz M. SZYMAŃSKI ${ }^{1}$, Sławomir SZRAMA ${ }^{2}$ \\ ${ }^{1}$ Poznan University of Technology, Institute of Transport \\ E-mail: daniel.mokrzan@student.put.poznan.pl, julia.milewicz@student.put.poznan.pl, \\ grzegorz.m.szymanski@put.poznan.pl \\ 231 st Tactical Air Force Base Poznań-Krzesiny \\ E-mail: slawomir.szrama@put.poznan.pl
}

\begin{abstract}
The paper presents the method of assessment of the technical condition of the leading edge of the horizontal stabilizer of an F-16 Block C aircraft made from composite materials. The described method was an experimental measurement of the acoustic pressures generated by the technically operational element and the element with the distorted structural continuity and then a comparison of these pressures in the curves of time and frequency in order to assess how the damage impacts the parameters of the acoustic wave. The test was performed in a dual-channel system, the pressure was induced through impacts on the investigated element with an impact hammer and then, based on the measured induction parameters and the generated acoustic wave, the function of frequency response was calculated, based on which the authors assessed how the structural damage influenced the curve characteristics of the acoustic pressure in the domain of frequency. The described method may be used as an efficient method of non-destructive diagnostics of the airframe elements of an aircraft.
\end{abstract}

Keywords: vibroacoustic analysis, non-destructive diagnostics, acoustic pressure, airframe, composite materials, spectral analysis, frequency response function

\section{ZASTOSOWANIE ANALIZY WIBROAKUSTYCZNEJ W OCENIE STANU TECHNICZNEGO KOMPOZYTOWYCH ELEMENTÓW PŁATOWCA STATKU POWIETRZNEGO}

Streszczenie

Artykuł przedstawia metodę oceny stanu technicznego krawędzi natarcia statecznika poziomego statku powietrznego F-16 Block C wykonanej z materiałów kompozytowych. Opisywaną metodę stanowił eksperymentalny pomiar ciśnienia akustycznego emitowanego przez element sprawny technicznie oraz element $\mathrm{z}$ naruszoną ciągłością struktury, a następnie porównanie ich przebiegu w domenie czasu oraz częstotliwości celem ustalenia w jaki sposób uszkodzenia wpływają na parametry emitowanej fali akustycznej. Badanie dokonywane było dwukanałowo, ciśnienie akustyczne wzbudzane było za pomocą uderzeń w badany element za pomocą młotka modalnego, następnie na podstawie zmierzonych parametrów wzbudzania oraz wywołanego nim fali akustycznej obliczono funkcję odpowiedzi częstotliwości, na podstawie której określono jak uszkodzenie struktury wpływa na przebieg charakterystyki ciśnienia akustycznego w dziedzinie częstotliwości. Opisywana metoda może służyć za skuteczną metodę diagnostyki nieniszczącej elementów płatowca statku powietrznego.

Słowa kluczowe: analiza wibroakustyczna, diagnostyka nieniszcząca, ciśnienie akustyczne, płatowiec, materiały kompozytowe, analiza widmowa, funkcja odpowiedzi częstotliwości

\section{INTRODUCTION}

One of the most commonly used materials in aircraft design are the widely understood composite materials. This term is referred to as a material composed of at least two components. The main components of a composite are the matrix and the reinforcement. The matrix fills the space among the reinforcement elements at the same time protecting them and forming the desired shape of the designed component. Such a solution makes composite materials relatively light, rigid and durable [1].
In aviation, fiber-based composite materials are used predominantly (the reinforcement made of fibers). They possess better mechanical and strengthrelated properties compared to other composites. The most frequently applied reinforcement are glass fiber, carbon fiber or aramid fiber. One of the latest composite materials used in aviation is GLARE (Glass Fiber Reinforced Aluminum Laminates) a solution combining the glass fiber with the aluminum laminates. Such a number of material configurations of the composites makes them the 
most dynamically advancing construction materials in aviation [2].

During their lifecycle, the elements of the airframe made of components are exposed to many factors that can potentially distort their structure. They are subject to fatigue caused by variable tensions resulting from the dynamic conditions of operation (the loads are extremely different when the aircraft is stationary, during takeoff, cruise and landing). Another factor influencing the risk of damage are foreign objects that can potentially hit the element [3].

The composites have different forms of damage than metals. They are resistant to corrosion but are sensitive given the fact that they are made from more than one component. They are prone to structural damage such as delaminating, loss of rigidity, splitting or cracks [4].

Delamination is one of the most frequent and dangerous defects occurring in the life cycle of a composite material. It results from impacts and short overheats of the structure. This leads to the loss of coherence between the layers leading to layer separation. This, in turn, leads to a reduced strength and exposure to further damage. Composites lose their rigidity in the process of operation, which may lead to further dysfunction of the element [5].

The multitude of damage that can occur to a composite material and its impact on the flight safety forced engineers to develop non-destructive diagnostic methods with a view to identifying all structural defects in their early stage - particularly those that a diagnostic technician is incapable of detecting with the naked eye. One of such methods is vibroacoustic diagnostics [5].

All the elements of the airframe are characterized by the fact that either during operation or when induced intentionally, they generate vibration and acoustic waves. The parameters of vibration and the sound wave are tightly related to the technical condition of the diagnosed object. All micro-damage and non-continuity of structure results in a change in these parameters. This makes vibroacoustic diagnostic a potentially efficient method of assessment of the technical condition of the airframe, including the composite elements [6].

The aim of this paper is to experimentally determine the differences between the parameters of the acoustic wave generated upon inducing an undamaged composite element of the airframe and the acoustic wave of the same, structurally damaged element. As a result, the authors will perform an assessment of the usefulness of the diagnostic method in the assessment of the technical condition of elements made of composite materials.

\section{AIRFRAME DIAGNOSTICS}

\subsection{Analysis of existing solutions}

Following the advancement in the area of application of composite materials in the construction of aircraft airframes and given the critical importance of a sufficiently early detection of damage to avoid the risk of loss of life of the passengers, research of the efficient non-destructive diagnostics of composite elements has become necessary.

One of the fundamental methods in vibroacoustic diagnostics is modal analysis. Its assumption is the determination of the dominating frequencies (modes) corresponding to the natural frequencies of a given structure based on the measurement of vibration or acoustic pressure. Based on the analysis of the singularities in the modes, one can detect the occurrence of damage and its type. Such a diagnostic method has already been successfully applied in the case of composites made from plastics reinforced with glass fiber (Glass Fiber Reinforced Plastic, GFRP). During the tests, the measurement of the vibration was used. The shapes of the modes were subsequently analyzed using advanced forms of signal processing such as the wavelet transform, which allowed detecting differences in the tested vibration modes compared to the modes of the undamaged part, hence diagnosing the structural damage [7].

Another method of vibroacoustic detection of composite damage successfully used in previous research is the pattern occurrence analysis involving acoustic pressure as the parameter used to determine the pattern. The authors measured the sound induced by an inducer and generated by the composite structures of damaged and undamaged elements. The number of measurements was set to enable an analysis of the normal distribution of the investigated pattern. Then, the authors compared the dominating frequencies of the acoustic signals for different types of damage of the composites and using the regression model assessed how a given damage influences the change in the dominating frequency in the investigated signal [8].

A topic rarely discussed in literature is the use of the assumptions of modal analysis using the acoustic pressure as the investigated parameter to assess the technical condition of a composite element.

\subsection{Vibroacoustic measurements of the airframe elements}

Contrary to the diagnostics of aircraft engines, tests of the airframe elements are not usually performed when in operation, particularly not during the flight. This is due to the fact that it is extremely difficult to measure the vibration of the airframe or the elements of the flight avionics at the aircraft cruising velocity. Under such conditions, it would be practically impossible to distinguish the acoustic pressure of an undamaged and damaged elements (micro-cracks generated during the tests) [4].

Diagnostically speaking, in such a case, an experimental method performed under controlled conditions turns out useful. Under the said controlled conditions the waves and acoustic vibration are induced on an element through a precisely defined shock. 
The induction can be a series of impacts with a hammer or an inducer that will generate the vibration. The signature of the vibration or the sound obtained in the test is compared to the signature and vibration of the reference element. Based on such a comparison one can determine the type of defect starting from micro-cracks through more serious damage. In operational practice under makeshift conditions (military), analyses without specialized equipment are performed. Certain structural damage can be identified based on the noise registered by the analyst (no aural amplification). This allows assuming that the measurement of the acoustic pressure under controlled conditions provides sufficiently accurate diagnostic information regarding the technical condition of an object [9-11].

\subsection{Spectrum analysis in measurement interpretation}

The measurements of the signals, both vibration and acoustic, are realized in the domain of time. Such an analysis provides accurate information as to the course of the signal in time. It is, however, difficult to apply in practice when determining the technical condition of an object particularly if the signal is complex and accompanied by distortions. For this reason, a transformation to the domain of frequency is applied that allows analyzing the signal from a different perspective by clarifying its components and determining the dominating frequencies [12].

The visualization of the differences between the signal presented in the domain of time and the domain of frequency has been shown in Fig. 1.

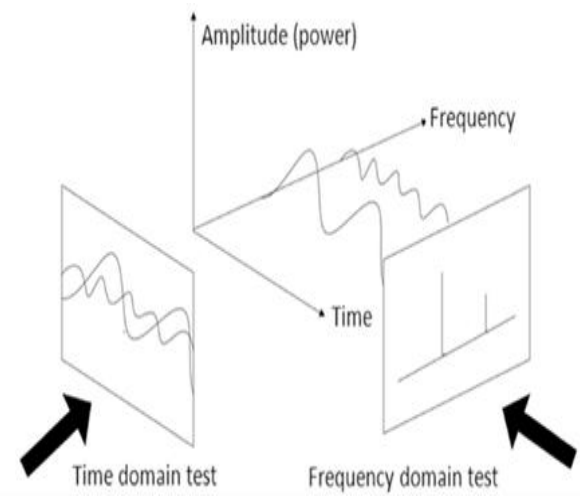

Fig. 1. Difference between the domain of time and the domain of frequency [13]

In the order to change a domain of signal from time to frequency, the Fast Fourier Transform (FFT) is used. There are several methods of calculating the FFT. One of them is using the Cooley-Tukey algorithm. Below, the authors present its application with time division and operation on the continuity of the signal value of the length of the power of 2 :

$\mathrm{N}$ samples of the acoustic signal $(\mathrm{N}$ is the power of 2). We divide this sequence into two sequences: $x_{p}(n), x_{n}(n)$, composed of the signal samples $x(n)$ of properly even $(0,2,4, \ldots)$ and odd $(1,3,5, \ldots)$ indexes. We calculate the Fourier transforms of these sequences: $X_{p}(n), X_{n}(n)$, triggering the recurrent FFT calculation procedure. Next, we compose the transform of the entire sequence of samples as per the relation:

$$
\begin{gathered}
X(k)=X_{p}(k)+W_{k}^{N} X_{n}(k) \\
X\left(k+\frac{N}{2}\right)=X_{p}(k)-W_{k}^{N} X_{n}(k) \\
W_{k}^{N}=e^{\frac{-2 \pi j k}{N}}
\end{gathered}
$$

For $0 \leq k \leq \frac{N}{2}$. Summarizing the FFT calculation with this algorithm consists in another division of samples into odd and even sequences until we obtain two-point sequences, for which $X(0)=x(0)+x(1), X(1)=x(0)-x(1) . \quad$ The final effect is the composition of the above two sequences of transforms into a whole, as a result of which we obtain the course of the signal as a function of frequency.

In the case of a dual-channel analysis, i.e., during diagnostics of the vibration signal and acoustic pressure triggered by a given impact, when we record the value of this impact and the parameters of the obtained signal, the Frequency Response Function (FRF) applies [14].

FRF presents the ratio of the output data to the input data and is expressed by equation 4 :

$$
H(f)=\frac{B(f)}{A(f)}
$$

where $\mathrm{B}(\mathrm{f})$ is the output signal in the domain of frequency and $\mathrm{A}(\mathrm{f})$ is the input signal in the domain of frequency.

The necessity to apply FRF results from the characteristics of the dual-channel analysis. The external impact applied to the investigated system is the input signal. This impact is necessary to make the system vibrate but as such does not constitute information on the technical condition of an object. FRF is a response to the applied impact and the way it influenced the input signal is the diagnostic information on the analyzed object [15].

\section{RESEARCH OBJECT}

During the experiment, the leading edge of the horizontal stabilizer of an F-16 aircraft was subjected to the test. At the time of the experiment the aircraft served at 31 Tactical Airbase in Poznań. General Dynamics F-16 Fighting Falcon is a multirole combat aircraft manufactured by Lockheed Martin. It is a one or two (training version) pilot aircraft. It is designed to fight air as well as ground targets. F-16 has a stressed skin (semi-monocoque) airframe design, mostly made from aluminum alloys with steel, titanium, composite and glass fiber elements [16].

The design schematics including the materials used for the construction have been shown in Fig. 2 . 


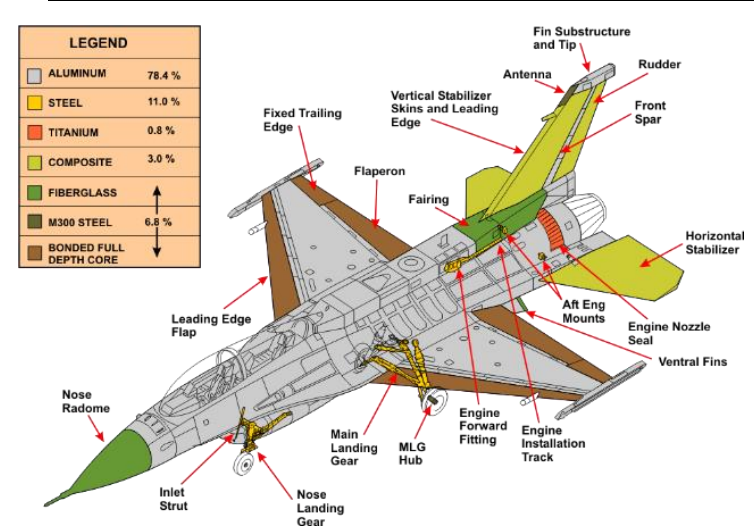

Fig. 2. Schematics of the F-16 aircraft and materials used for its production [17]

The object under analysis is a component of an element referred to as the 'horizontal stabilizer', and more specifically its leading edge. Its more detailed schematics have been shown in Fig. 3.

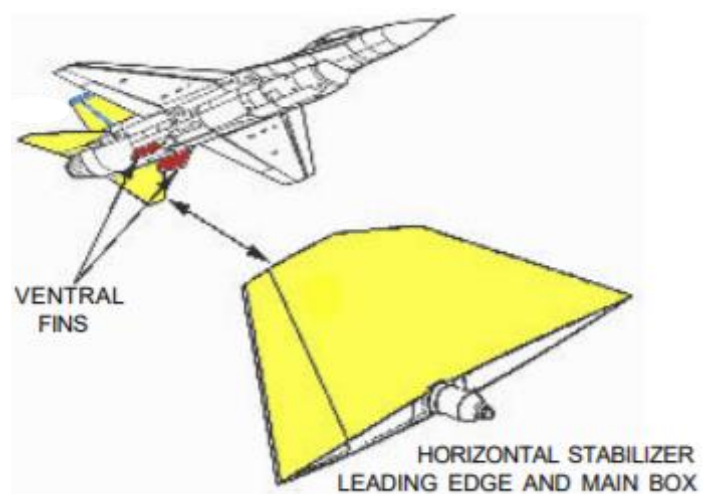

Fig. 3. Schematics of the horizontal stabilizer [17]

The component shown in Fig. 3 is made from composite materials. The aluminum core is covered with a sealing material and a graphite paneling. The binder is the epoxy. The acoustic signal of a structurally undamaged element was compared with the damaged one at the spot where the structure continuity was lost due to the interaction with a foreign object (Foreign Object Damage, FOD). The actual view of the investigated object has been shown in Fig. 4.

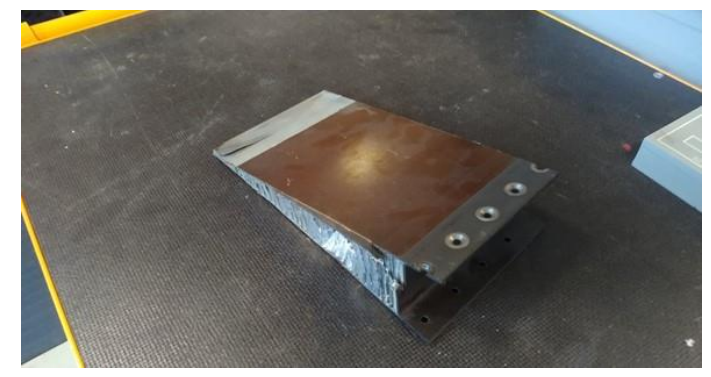

Fig. 4. Horizontal stabilizer- the tested example

The distortion of the continuity of the element structure has been shown in Fig. 5 .

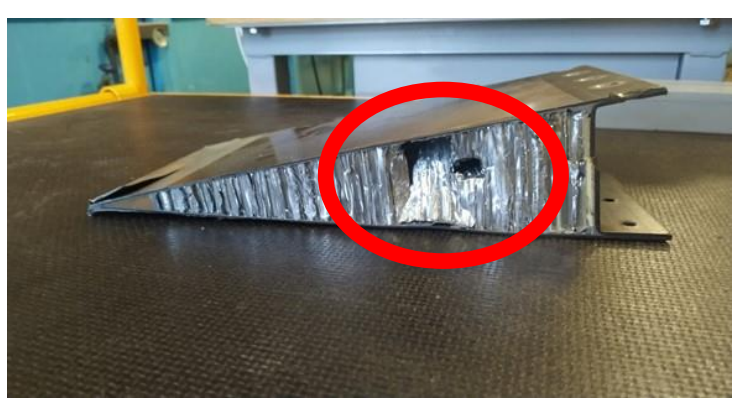

Fig. 5. Horizontal stabilizer damage

The damage in the structure of the stabilizer, as shown in Fig. 5, is visible with the naked eye upon element disassembly. It is sufficiently extensive for the component to be assigned for renewal.

\section{RESEARCH METHODOLOGY}

The investigations pertained to the influence of structural damage of a technical object on the course of the pressure signal of the acoustic wave recorded during the experiment. In the test, the authors utilized an impulse test. The acoustic wave was generated by the impacts on the tested element with an impact hammer. The signal was recorded with two microphones positioned perpendicularly against each other. The recording continued under stable acoustic conditions and was paused if noises that could influence the results appeared (e.g., takeoffs of other F-16 aircraft). Then, the signal was processed with a measurement cassette and saved on an external memory card. Each measurement series was saved in a separate file. The measurement series had 30 impacts each.

The measurement equipment used during the tests has been shown in Fig. 6, 7 and 8.

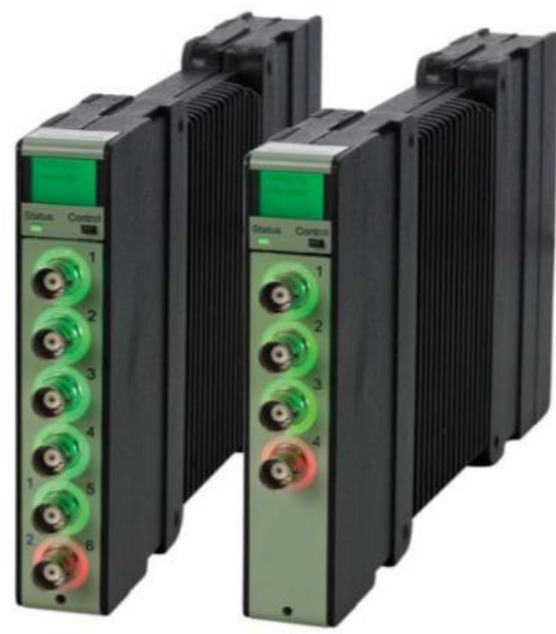

Fig. 6. Data acquisition module (Brüel \& Kjær 3050) - image provided by the manufacturer

For the acquisition and processing of the recorded data, the authors used the fast-varying signal processing unit (3050) by Brüel\&Kjær shown in Fig. 6. The equipment allows measuring the sound 
and vibration using 6 input channels simultaneously and supplies power to the microphones of the voltage of $200 \mathrm{~V}$. The acquisition unit can record signals with the sampling frequency of 131072 samples per second.

In the impulse test, an impact hammer (8206) by Brüel\&Kjær was used (Fig. 7) of the sensitivity of $22.7 \mathrm{mV} / \mathrm{N}$ fitted with an accelerometer allowing the measurements of the response of the tested structure to the impacts.

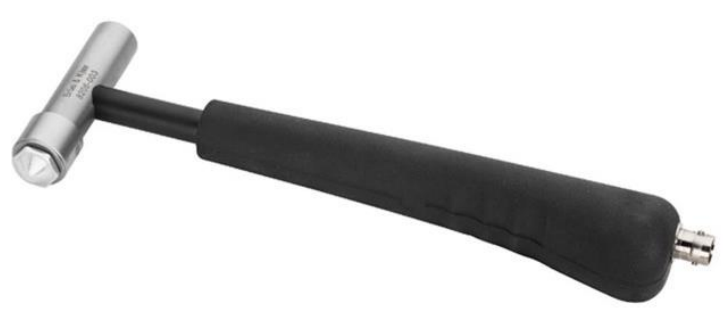

Fig. 7. Impact hammer- Brüel\&Kjærtyp 8206 - image provided by the manufacturer

The hammer was fitted with an accelerometer allowing the measurements of the response of the tested structure to the impact with the possibility of application in the FRF calculations.

For the measurement of the pressure of the acoustic wave, the authors used two microphones by Brüel\&Kjær (4189-A-021), shown in Fig. 8, of the recording frequency range of $20 \mathrm{~Hz}-20 \mathrm{kHz}$ and the sensitivity of $50 \mathrm{mV} / \mathrm{Pa}$.

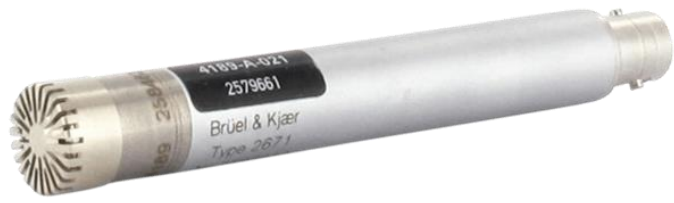

Fig. 8. The microphone - Brüel\&Kjær A-021 - image provided by the manufacturer

The microphones were positioned perpendicularly against each other.

\section{RESULTS}

\subsection{Analysis of the time tracings}

Upon completion of the tests and saving of the results, the results were imported to the analytical software by Brüel\&Kjær (BK Connect - Data processing module), with which the authors performed a preliminary analysis of the tracings of the acoustic pressure recorded by the microphones and the impact forces in the domain of time. Low quality results and those diagnostically negligible were rejected (sounds recorded following incidentally repeated hammer impacts).

The tracings of the recorded signal in time for the measurements of the correctly performed impacts on the undamaged element have been shown in Fig. 9. and Fig. 10.

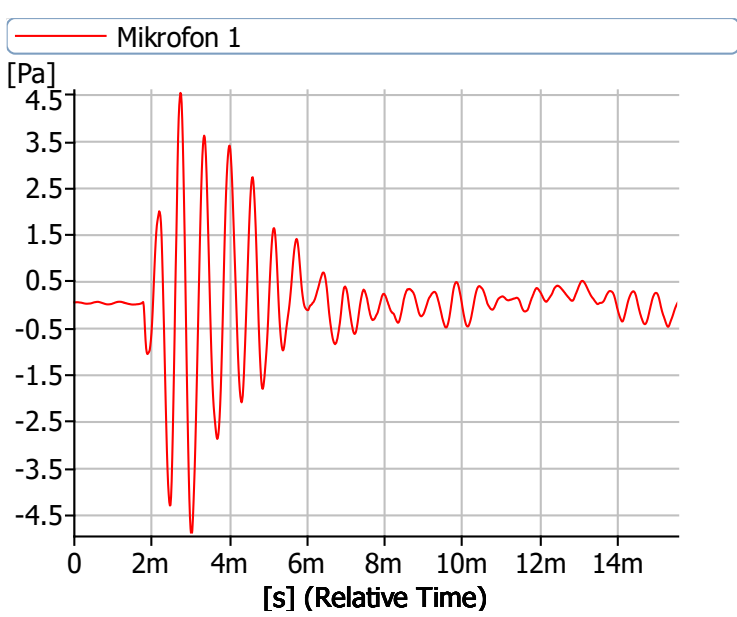

Fig. 9. Time tracing of the signal of the undamaged element from microphone 1

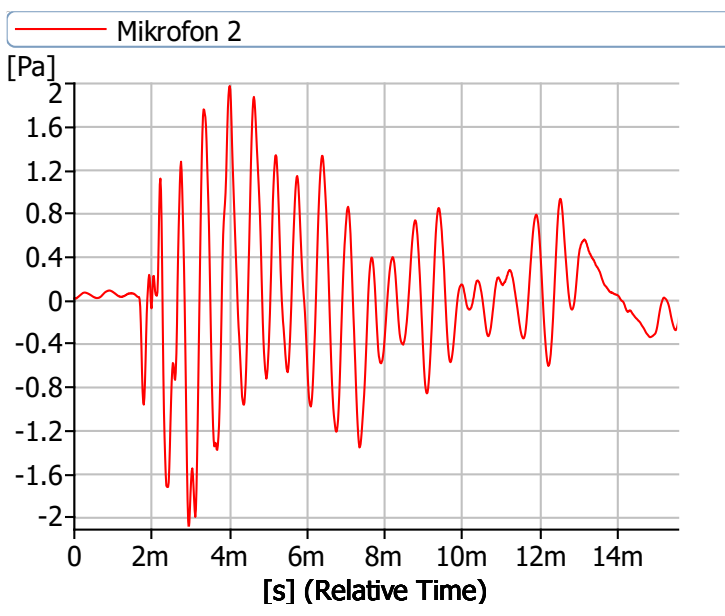

Fig. 10. Time tracing of the signal of the undamaged element from microphone 2

The tracings of the recorded signal in time for the performed measurements for correctly performed impacts have been shown in Fig. 11. and Fig. 12.

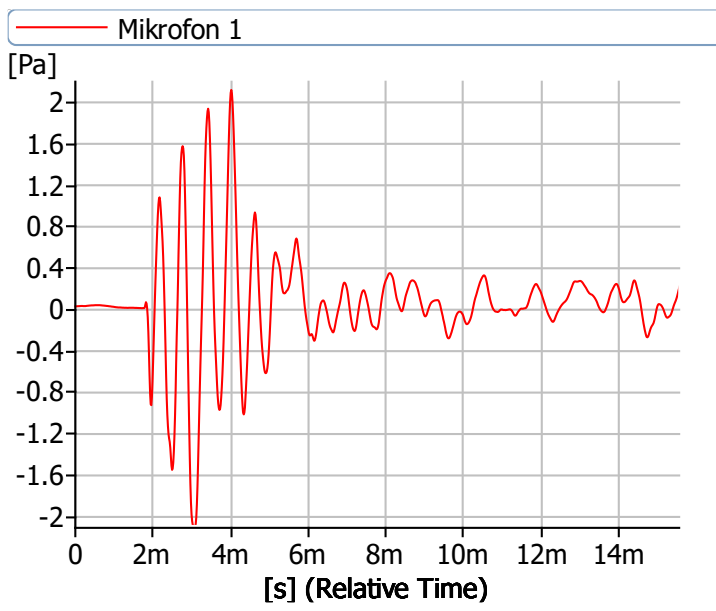

Fig. 11. Time tracing of the signal of the damaged element for microphone 1 


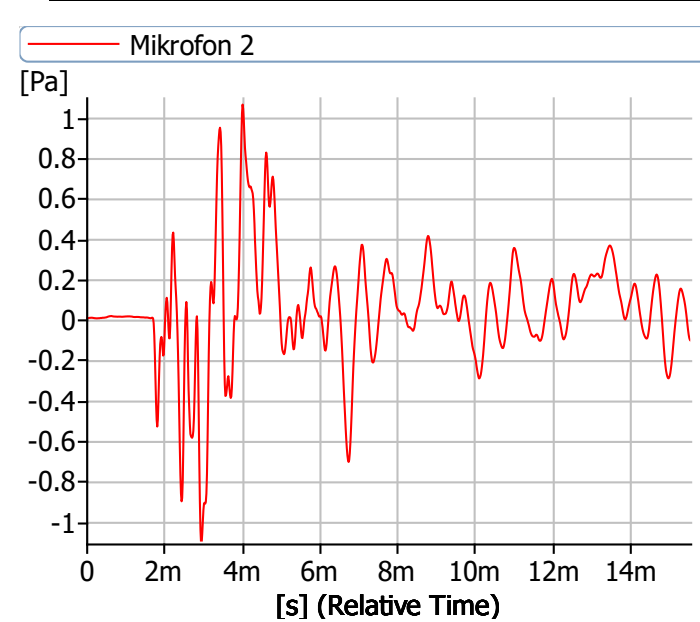

Fig. 12. Time tracing of the signal of the damaged element for microphone 2

Based on Figs. 9-12 one can observe that the positioning of the microphones was impactful on the way they recorded the sound. Microphone 1 received a more unified signal, of high amplitude and short period, while the signal received by microphone 2 had the nature of an extended echo of lower amplitude and longer period.

Exclusively based on the time tracings, it is difficult to determine the technical condition of the element let alone the differences between the damaged and undamaged objects. Therefore, it is recommended to transform the obtained results from the domain of time to the domain of frequency.

\subsection{Spectral analysis of the acoustic pressure measurement results}

Comparing the signal tracings in time and drawing useful diagnostic information from this comparison would be rather difficult, as the overlaying of the tracings alone of the undamaged and damaged elements would already blur the picture rather than facilitate its analysis.

For this reason, the authors decided to shift to the domain of frequency to obtain an amplitude spectrum of the signal. The transformation was performed using the FFT. Owing to the dual channel recording, the tracings are the FRF ones for individual cases.

The transformation was performed for the signal recorded by microphone 1 for the impacts on the damaged and undamaged elements. Thus, obtained amplitude spectrum for both measurements was overlain on a single graph and compared in Fig. 13.

Based on Fig. 13, we can distinguish two tracings in the domain of frequency. The red tracing visualizes the signature of the sound for the undamaged element, and the blue one for the damaged element.

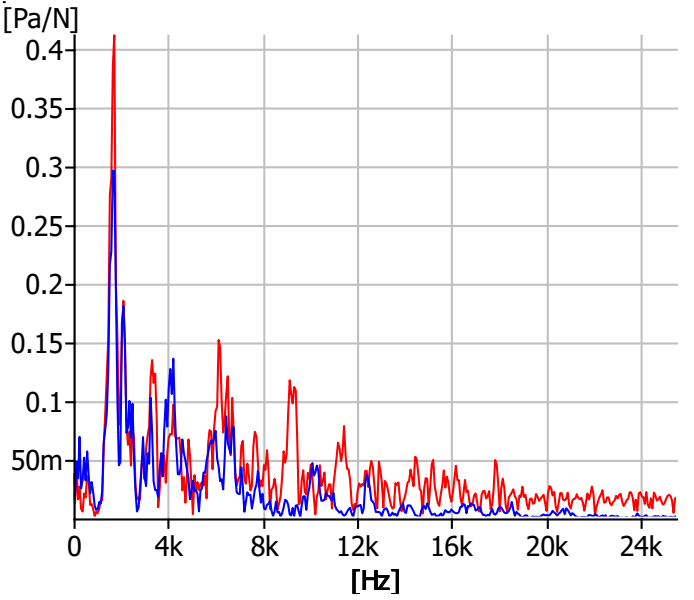

Fig. 13. Comparison of the FRF tracing for the damaged (blue) and undamaged (red) elements for microphone 1

The difference between the tracings we can see by reading the amplitude and the shift of the frequency. The amplitude difference at low frequency ranges results from the differences in the impact force. When analyzing the tracings in the higher frequency ranges one can observe a damping in the damaged element.

The diagnostically significant differences can be seen upon enlarging to the range of 9000-10000 $\mathrm{Hz}$ in Fig. 14.

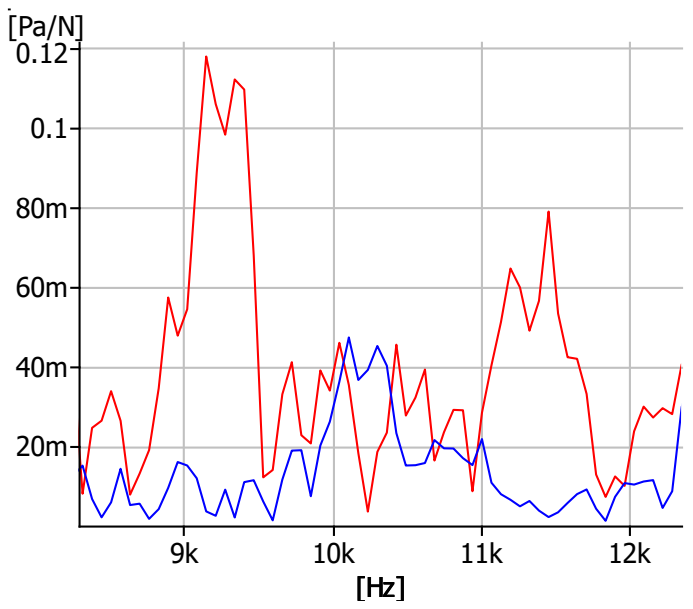

Fig. 14. Comparison of the FRF tracing for the damaged (blue) and undamaged (red) elements (enlarged)

In Fig. 14 one can see an already significant damping in the higher frequency range, which is characteristic of structural damage. In order to confirm the influence of the defect on the signal damping, six impacts on the undamaged element and six impacts on the damaged element were analyzed and compared on the decibel graphs. 


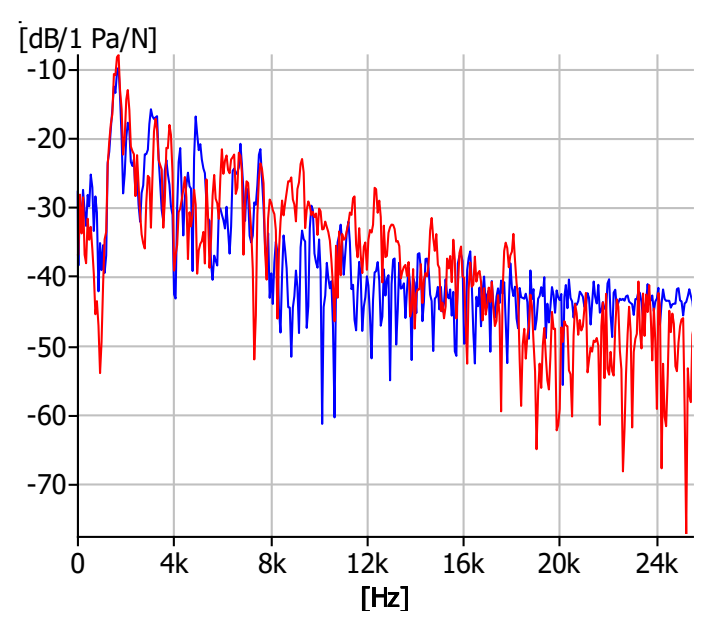

Fig. 15. Comparison of the FRF tracing for the damaged (blue) and undamaged (red) elements for the first impact of the hammer

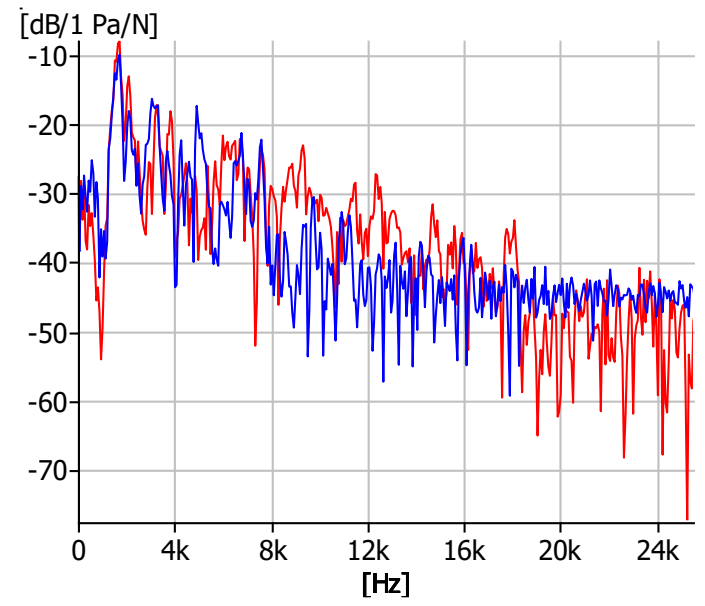

Fig. 16. Comparison of the FRF tracing for the damaged (blue) and undamaged (red) elements for the second impact of the hammer

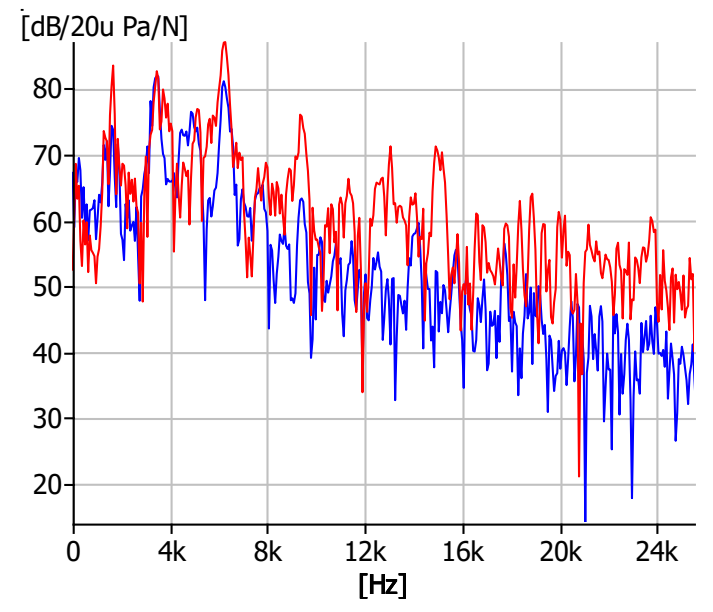

Fig. 17. Comparison of the FRF tracing for the damaged (blue) and undamaged (red) elements for the third impact of the hammer

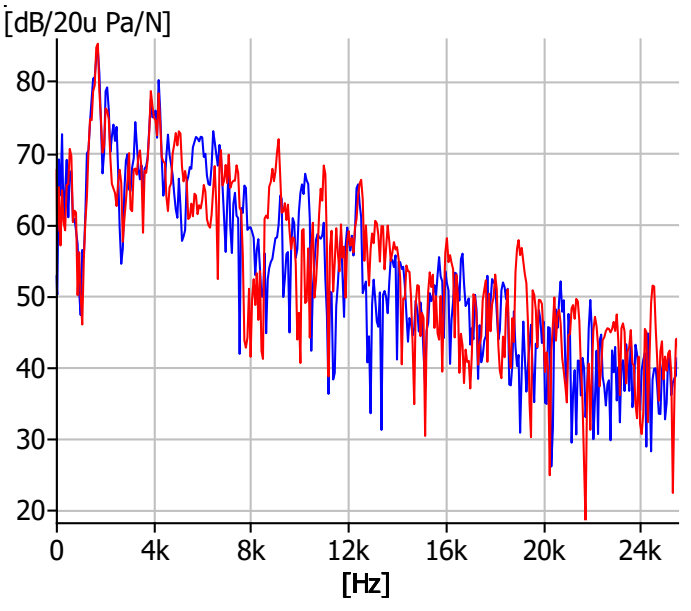

Fig. 18. Comparison of the FRF tracing for the damaged (blue) and undamaged (red) elements for the fourth impact of the hammer

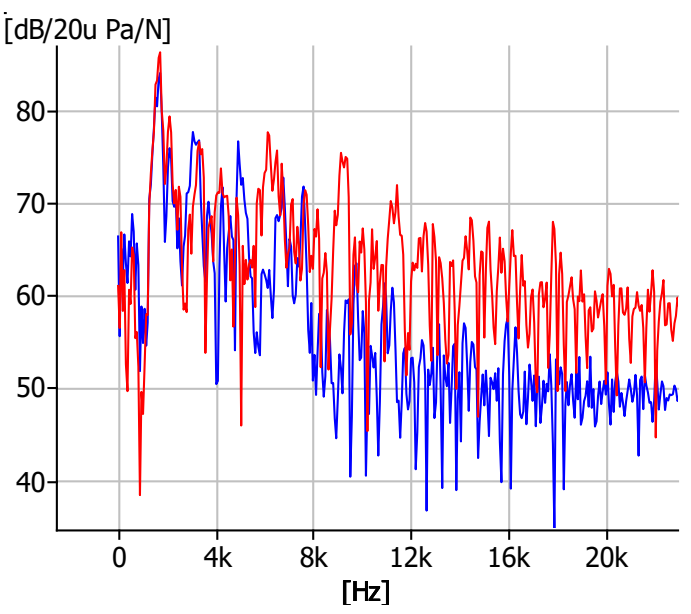

Fig. 19. Comparison of the FRF tracing for the damaged (blue) and undamaged (red) elements for the fifth impact of the hammer

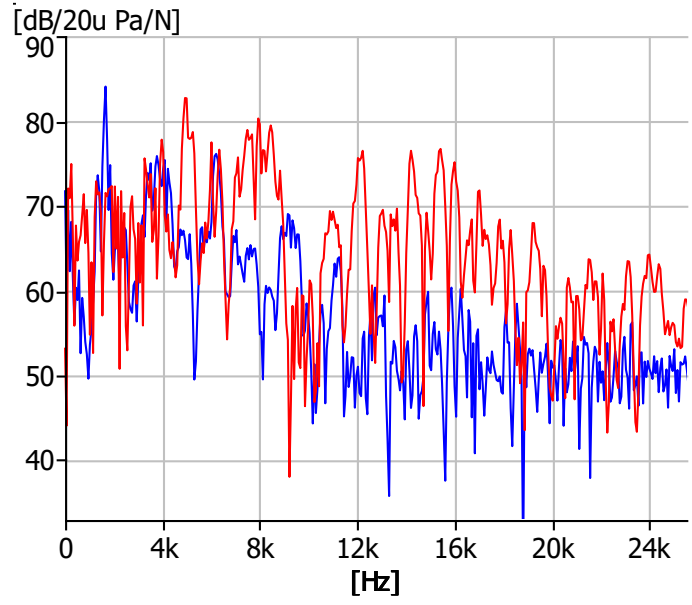

Fig. 20. Comparison of the FRF tracing for the damaged (blue) and undamaged (red) elements for the sixth impact of the hammer 
When analyzing the FRF graphs, we can observe in the logarithmic scale that in the lower frequency range up to $8000 \mathrm{~Hz}$ the tracings of the acoustic pressure levels are convergent and there are no diagnostically significant differences. The differences can be observed only for the frequencies above $8 \mathrm{kHz}$ and the greatest differences are visible for the frequencies oscillating around $9 \mathrm{kHz}$ and 15 $\mathrm{kHz}$ where the divergence between the points representing the acoustic pressure level of the undamaged and damaged elements in a given range reaches $30 \mathrm{~dB}(6 \mathrm{~dB}$ is sufficient to identify structural damage).

The comparison of the frequency tracings for all 6 impacts indicated that in the case of the damaged element acoustic damping occurs at higher frequencies (reaching $30 \mathrm{~dB}$ ) compared to the element without a defect, which confirms the assumption that structural damages have a clear damping effect on the spectrum.

\subsection{Statistical analysis of the results}

From the operational and diagnostic practice one can assume that majority of the operating and diagnostic parameters of the aircraft components can be described within a scope confined with a typical interval of variability. Such a practice, even though this law should be applied for normal distribution, allows it to be used for samples smaller than 30 . Using the above, we can determine the differences in the amplitude characteristic of differences between a damaged and an undamaged element. The authors decided to analyze how the difference between the amplitudes of both elements changed during the 6 impact trials.

According to the assumptions of typical interval of variability, $66.7 \%$ of the value of such an area is within the range of tolerance $\{x-\sigma ; x+\sigma\}$, where $\mathrm{x}$ is the average value. The following algorithm was used, and the following were calculated [18]:

- arithmetic average $\bar{x}$ of the acoustic frequency value in a given interval:

$$
\bar{x}=\sum_{i=1}^{n} x_{i}
$$

- average square deviation (variance):

- standard deviation

$$
s^{2}=\frac{1}{n} \sum_{i=1}^{n}\left(x_{i}-\bar{x}\right)^{2}
$$

$$
\sigma=\sqrt{s^{2}}
$$

The frequency of $14.912 \mathrm{kHz}$ was selected for analysis. The amplitude tracing for different impacts has been shown in Tab. 1.

The average difference was:

$$
\bar{x}=11,37 d B
$$

The standard deviation was:

$$
\sigma_{1}=4,53 \mathrm{~dB}
$$

which, rendered the following ranges of tolerance:

$$
x=<6,84 d B ; 15,89 d B>
$$

Tab. 1. Analysis of the amplitude difference between the damaged and undamaged element for the frequency of $14.912 \mathrm{kHz}$

\begin{tabular}{|c|c|c|c|}
\hline $\begin{array}{c}\text { Number } \\
\text { of impact }\end{array}$ & $\begin{array}{c}\text { Amplitude of } \\
\text { undamaged } \\
\text { element [dB] }\end{array}$ & $\begin{array}{c}\text { Amplitude of } \\
\text { damaged } \\
\text { element [dB] }\end{array}$ & $\begin{array}{c}\text { Difference } \\
\text { [dB] }\end{array}$ \\
\hline 1 & $-33,904$ & $-42,974$ & 9,07 \\
\hline 2 & $-33,902$ & $-44,878$ & 10,976 \\
\hline 3 & 71,261 & 52,342 & 18,919 \\
\hline 4 & 51,339 & 44,967 & 6,372 \\
\hline 5 & 64,745 & 49,101 & 15,644 \\
\hline 6 & 67,077 & 59,854 & 7,223 \\
\hline
\end{tabular}

The conclusion is that in the case of $66.7 \%$ impacts, we can expect a difference in the amplitude in the range from $6.84 \mathrm{~dB}$ to $15.89 \mathrm{~dB}$ between the undamaged and the damaged element. If the difference is at least $6 \mathrm{~dB}$, we can assume a structural defect of the element. The statistical analysis and the fact that for none of the impacts for the analyzed frequency the differences were lower than $6 \mathrm{~dB}$, confirm that the performed tests and the spectrum analysis allowed a correct identification and description of the differences in the tracings of the acoustic signal between the undamaged and damaged element.

\section{CONCLUSIONS}

In the paper, the authors have analyzed the possibility of application of a method of assessment of the technical condition of composite elements of an airframe using vibroacoustic diagnostics.

The authors have investigated an element of a multirole F-16 aircraft - an undamaged and damaged leading edge of the horizontal stabilizer. The experiment was performed based on generating a simulated impact vibration on the elements with an impact hammer and then recording of the vibration with two microphones and a cassette. The acoustic wave was recorded, and the obtained data were processed with specialized software. Acoustic pressure was adopted as the diagnostic parameter. The authors changed the domain of the signal from time to frequency thus obtaining the amplitude spectrum graph. The graphs obtained in this way were compared with one another. The conclusions from this comparison were as follows: the analysis should be performed on the differences in the amplitude and frequency range. Given that the structural defects have a damping effect on the course of the signal, the authors focused on the description of differences in the amplitudes between the undamaged and damaged element caused by the said damping effect. Results of low quality were eliminated (the effects of a double impact). Following the spectral analysis, the authors precisely analyzed six series of impacts on the undamaged and damaged element. When comparing the courses of the frequency characteristics being the results of the impacts, the authors concluded that the structural defects cause damping of the sound amplitude in the 
higher frequency range (over $8 \mathrm{kHz}$ ). This was confirmed by the statistical analysis, with which, for the selected frequency (higher range), the amplitude differences were compared and proved to be lower than $6 \mathrm{~dB}$, i.e. from the limit, above which structural damage of an element is assumed.

Based on the performed experiments, the authors observed that vibroacoustic analysis might be an efficient method of non-destructive examination of composite elements of an aircraft. One should note, however, the possible distortions and sensitivity of this method. Regular aircraft maintenance is usually carried out using airport infrastructure that is rather characteristic for its noise coming from aircraft takeoffs and landings. Any external distortions, including the ones resulting from the errors of the researcher (incorrect hammer impacts) are of vital importance for the results. In order to reduce the uncertainty of the measurements, one should properly prepare the testing environment (sound insulation), make sure the impacts are accurate and correct and ensure a sufficient number of measurement series to make them statistically viable.

\section{ACKNOWLEDGEMENTS}

The presented results have been co-financed from the subsidies appropriated by the Ministry of Science and Higher Education - 0416/SBAD/0001.

\section{REFERENCES}

1. Breuer UP. Commercial Aircraft Composite Technology. Cham: Springer International Publishing; 2016. https://doi.org/10.1007/978-3-319-31918-6.

2. Lubin G. Handbook of Composites. Boston, MA: Springer US; 1982. https://doi.org/10.1007/978-14615-7139-1.

3. Mangalgiri PD. Composite materials for aerospace applications. Bulletin of Materials Science 1999;22:657-664. https://doi.org/10.1007/BF02749982

4. Diamanti K, Soutis C. Structural health monitoring techniques for aircraft composite structures. Progress in Aerospace Sciences 2010;46:342-352. https://doi.org/10.1016/j.paerosci.2010.05.001.

5. Ghobadi A. Common Type of Damages in Composites and Their Inspections. World Journal of Mechanics 2017;7:24-33. https://doi.org/10.4236/wjm.2017.72003.

6. Salawu OS. Detection of structural damage through changes in frequency: a review. Engineering Structures 1997;19:718-723. https://doi.org/10.1016/S0141-0296(96)00149-6.

7. Katunin A, Dragan K, Dziendzikowski M. Damage identification in aircraft composite structures: A case study using various non-destructive testing techniques. Composite Structures 2015;127:1-9. https://doi.org/10.1016/j.compstruct.2015.02.080.

8. Gutkin R, Green CJ, Vangrattanachai S, Pinho ST, Robinson P, Curtis PT. On acoustic emission for failure investigation in CFRP: Pattern recognition and peak frequency analyses. Mechanical Systems and
Signal Processing 2011;25:1393-1407.

https://doi.org/10.1016/i.ymssp.2010.11.014.

9. Teter A, Gawryluk J. Experimental modal analysis of a rotor with active composite blades. Composite Structures 2016;153:451-467. https://doi.org/10.1016/j.compstruct.2016.06.013.

10. Oruganti K, Mehdizadeh M, John S, Herszberg I. Vibration-based analysis of damage in composites. Materials Forum 2008;33:496-504.

11. Randall RB. Vibration-based Condition Monitoring. Chichester, UK: John Wiley \& Sons, Ltd; 2011. https://doi.org/10.1002/9780470977668.

12. Rao KD. Signals and Systems. Cham: Springer International Publishing; 2018.

https://doi.org/10.1007/978-3-319-68675-2.

13. Sun J. Research on vocal sounding based on spectrum image analysis. EURASIP Journal on Image and Video Processing 2019;2019:4. https://doi.org/10.1186/s13640-018-0397-0.

14. He J, Fu Z-F. Frequency response function measurement. Modal Analysis. 1st ed., Oxford: Butterworth-Heinemann; 2001: 140-158. https://doi.org/10.1016/B978-075065079-3/50007-3.

15. Hill G. Frequency Response. Loudspeaker Modelling and Design, New York, NY: Routledge, [2019]: Routledge; 2018: 7-12. https://doi.org/10.4324/9781351116428-5.

16. Roskowicz M, Smal T, Szrama S. New challenges and technologies related to aircrafts' battle damages. Scientific Journal of the Military University of Land Forces 2018;188:208-223. https://doi.org/10.5604/01.3001.0012.2509.

17. HQ AFCESA Fire and Emergency Services. TECHNICAL ORDER 00-105E-9 2006.

18. Casella G, Berger RL. Statistical inference. 2nd ed. Cengage Learning; 2001

Received 2020-11-23

Accepted 2021-02-29

Available online 2021-03-30

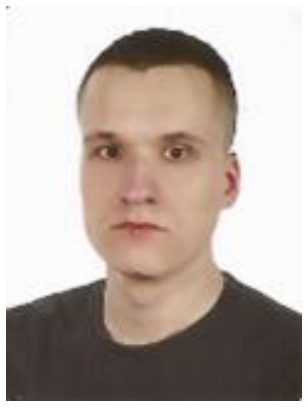

Daniel MOKRZAN B.Sc.Eng., a master's student at Institute of Transport, Faculty of Civil and Transport Engineering, Poznan University of Technology. His main research interests include data science and non-destructive diagnostics of technical elements, especially vibration and acoustic based assessment of a technical condition.

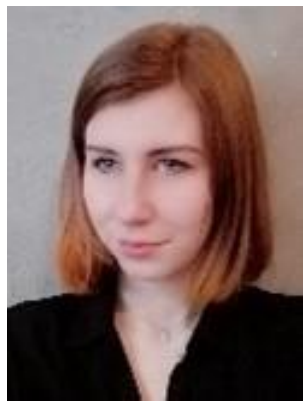

Julia MILEWICZ B.Sc.Eng., a master's student at Institute of Transport, Faculty of Civil and Transport Engineering, Poznan University of Technology. Her main research interests include data science and digital signal processing in the aspect of an assessment of technical condition of machines and vehicles. 


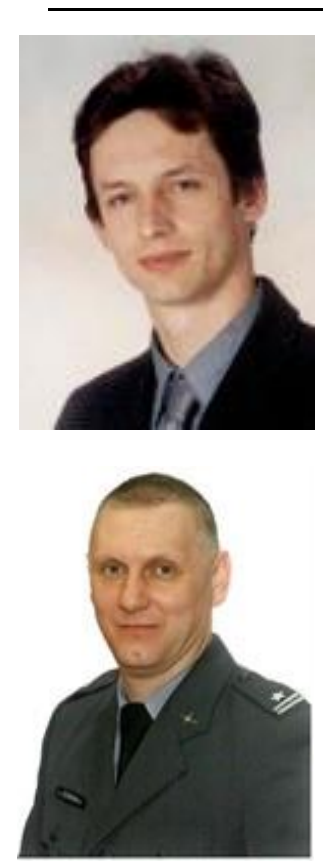

Grzegorz M. SZYMAŃSKI

DSc., DEng., an associate professor at Institute of Transport, Faculty of Civil and Transport Engineering, Poznan University of Technology. His main research interests include vibroacoustic diagnostics of vehicles and their component and an assessment of their vibration and noise levels.

\section{Slawomir SZRAMA DSc.,} DEng., a Squadron Commander at 31st Tactical Air Force Base Poznań-Krzesiny with 25 years' experience of aircraft maintenance (15 years with F-16s). His main research interests include aviation, problems of aircraft reliability and airworthiness, airframe and engines diagnostics. 